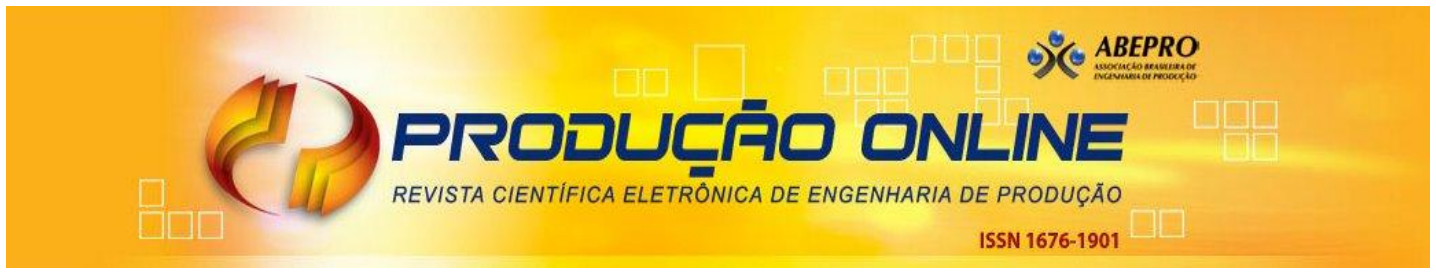

\title{
GESTÃO DA CADEIA DE SUPRIMENTO E VANTAGEM COMPETITIVA RELACIONAL NA INDÚSTRIA DE CALÇADOS
}

\section{SUPPLY CHAIN MANAGEMENT AND RELATIONAL COMPETITIVE ADVANTAGE IN FOOTWEAR INDUSTRY}

\author{
Fernando Luiz Emerenciano Viana* E-mail: fernandoviana@unifor.br \\ José de Paula Barros Neto** E-mail: jpbarros@ufc.br \\ Miguel Eduardo Moreno Añez $z^{* * *}$ E-mail: anez1957@yahoo.com.br \\ *Universidade de Fortaleza (UNIFOR), Fortaleza, CE \\ **Universidade Federal do Ceará (UFC). Fortaleza, CE \\ ***Universidade Federal do Rio Grande do Norte (UFRN), Natal, RN
}

\begin{abstract}
Resumo: Este artigo tem como objetivo geral investigar a contribuição da gestão da cadeia de suprimento para a obtenção de vantagem competitiva por empresas da indústria de calçados, com foco principal na análise das relações interorganizacionais. Utilizou-se para tal um modelo de análise desenvolvido por Viana (2010), cujo principal suporte teórico é dado pela visão relacional (DYER; SINGH, 1998). Trata-se de um estudo de casos múltiplos interpretativo, englobando duas empresas do setor calçadista que atuam no Ceará, em cuja análise de dados foi aplicado o método das comparações constantes, com o auxílio do software Atlas/ti. Em linhas gerais, percebeu-se que nos relacionamentos das empresas com seus fornecedores predomina o regime de parceria e são aplicados os principais pressupostos da gestão da cadeia de suprimento, o que contribui para a obtenção de vantagem competitiva relacional. Nas relações das empresas com o Governo e as instituições de fomento, os incentivos fiscais constituem o principal recurso acessado, os quais contribuem para a obtenção de vantagem competitiva temporária em relação aos concorrentes que não possuem instalações produtivas no Nordeste, bem como levam à situação de paridade competitiva em relação aos concorrentes que possuem instalações produtivas na Região Nordeste a aos concorrentes no mercado externo.
\end{abstract}

Palavras-chave: Vantagem Competitiva. Gestão da Cadeia de Suprimento. Visão Relacional. Indústria de Calçados. Relações Interorganizacionais.

\begin{abstract}
This work investigated the supply chain management contribution to competitive advantage for companies in the footwear industry, with a primary focus on the inter-organizational relationship analysis. It was used an analysis model developed by Viana (2010), whose main theoretical support is given by relational view (DYER; SINGH, 1998). It is an interpretive multiple case study, including two companies that operate in Ceará State. The data analysis procedure used the constant comparison method, with the Atlas/ti software assistance. In general, it is realized that in the buyers-suppliers relationships prevails the partnership and the main assumptions of supply chain management are applied, which contributes for the relational competitive advantage. In the relationships between enterprises and the government and development institutions, tax incentives are the main resource accessed, which contribute for temporary competitive advantage over competitors that do not have production facilities in the Northeast region as well as lead to a competitive parity situation to competitors that have production facilities in the Northeast region and to the external market competitors.
\end{abstract}

Keywords: Competitive Advantage. Supply Chain Management. Relational View. Footwear Industry. Inter-organizational Relationships.

Revista Produção Online, Florianópolis, SC, v.14, n. 4, p.1404-1432, out./dez. 2014. 


\section{INTRODUÇÃO}

Quando se discute a questão da vantagem competitiva, percebe-se que algumas correntes teóricas têm sido utilizadas (PENG, 2008), destacando-se a teoria dos recursos (VASCONCELOS; CYRINO 2000). Os primeiros trabalhos sobre vantagem competitiva baseada em recursos surgiram, de certo modo, como um contraponto à visão estrutural da vantagem competitiva (BARNEY, 1991; GRANT, 1991; PETERAF, 1993). Desde então, a teoria dos recursos vem evoluindo para uma visão mais abrangente, a qual considera a importância dos chamados recursos relacionais, bem como do ambiente institucional no qual as firmas estão inseridas, para a formação de vantagem competitiva. Assim, no presente trabalho considera-se o escopo da teoria dos recursos adotado por Acedo, Barroso e Gallan (2006), denominada Teoria Baseada em Recursos (TBR), a qual é utilizada como suporte teórico à análise da contribuição da gestão da cadeia de suprimento para a obtenção de vantagem competitiva.

Ao mesmo tempo em que existem diferentes teorias que buscam explicar as possíveis fontes de obtenção de vantagem competitiva, esta é muitas vezes atribuída às práticas de gestão utilizadas pelas organizações. Nesse contexto, a gestão da cadeia de suprimento (SCM - Supply Chain Management) surge como um importante elemento que pode favorecer a obtenção de vantagem competitiva.

No intuito de permitir a avaliação da contribuição da gestão da cadeia de suprimento para a obtenção de vantagem competitiva, Viana (2010) desenvolveu um modelo de análise que utiliza a teoria baseada em recursos como suporte teórico à análise das contribuições do SCM, com maior ênfase na visão relacional (DYER; SINGH, 1998).

Este trabalho tem como objetivo geral investigar a contribuição da gestão da cadeia de suprimento para a obtenção de vantagem competitiva por empresas da indústria de calçados, tendo como foco principal de análise as relações interorganizacionais (díades). Para tal, foram delineados dois objetivos específicos: (i) Caracterizar os relacionamentos interorganizacionais das empresas pesquisadas com seus fornecedores e; (ii) Avaliar a contribuição das relações entre as empresas e alguns componentes do ambiente institucional para a obtenção de vantagem competitiva. 
Para atender aos objetivos propostos, além dessa introdução, a estrutura do artigo contém os tópicos que se seguem: o referencial teórico, que aborda a teoria baseada em recursos, a gestão da cadeia de suprimento e o modelo de análise utilizado; os procedimentos metodológicos aplicados; a análise dos resultados e discussão sobre os mesmos e; a conclusão, seguida das referências utilizadas.

\section{REFERENCIAL TEÓRICO}

Observa-se que a teoria baseada em recursos vem evoluindo e se constituindo em um campo teórico marcante para a os estudos sobre vantagem competitiva. Uma empresa que possui vantagem comparativa em recursos, em relação aos concorrentes, obtém vantagem competitiva no mercado (HUNT; DAVIS, 2008).

Segundo Brito e Brito (2012), as empresas capazes de criar mais valor são aquelas que apresentam uma vantagem competitiva frente aos seus concorrentes. A superioridade na criação de valor propicia capacidade de manobra e implementação de estratégias competitivas alinhadas com a proposição de valor da empresa. Deste modo, os recursos e competências podem desempenhar um papel chave na geração de valor superior.

Tendo-se o escopo da TBR supracitado como referência e considerando-se o objetivo geral do trabalho, torna-se relevante a utilização de uma visão cujo foco está nos relacionamentos da firma com os componentes da cadeia de suprimento. De acordo com Dyer e Singh (1998), as ligações exclusivas interfirmas podem ser uma fonte de ganhos relacionais e vantagem competitiva e, nesse contexto, apresentam a visão relacional, que tem o foco sobre as rotinas e processos diádicos ou de rede como uma importante unidade de análise para o entendimento da vantagem competitiva.

Consoante Duschek (2004), a perspectiva da visão relacional considera que os recursos críticos para a vantagem competitiva não estão necessariamente alojados dentro da empresa, podendo os mesmos estar além das fronteiras da firma, imersos em processos e rotinas interorganizacionais, ou seja, na cadeia de suprimento. 
Define-se um ganho relacional como um lucro acima do normal gerado a partir de contribuições idiossincráticas conjuntas dos parceiros específicos de uma aliança (DYER; SINGH, 1998). Os ganhos relacionais são possíveis nas ocasiões em que as firmas parceiras combinam, trocam ou investem conjuntamente em ativos idiossincráticos, recursos, conhecimentos e habilidades e/ou empregam mecanismos de governança efetivos que diminuem os custos de transação. De modo resumido, as quatro fontes de ganhos relacionais são: (1) investimentos em ativos específicos para a relação; (2) troca substancial de conhecimento, incluindo a troca de conhecimento que resulta em aprendizagem conjunta; (3) combinação de recursos e capacidades e competências complementares, porém escassos, que resultam na criação conjunta de novos produtos, serviços ou tecnologias únicas e; (4) baixos custos de transação em relação a alianças competidoras, devido a mecanismos de governança mais efetivos.

A obtenção de ganhos relacionais e de vantagem competitiva depende diretamente do desenvolvimento e da manutenção de competências relacionais (LADO; PAULRAJ; CHEN, 2011). Wieland e Wallenburg (2012), por sua vez, destacam o papel de três competências relacionais como influenciadoras da geração de valor superior em uma cadeia de suprimento: comunicação, cooperação e integração.

A visão relacional também destaca a importância de que sejam buscados mecanismos que preservem os ganhos relacionais. Somados aos mecanismos relacionados às características que tornam os recursos imperfeitamente imitáveis (BARNEY, 1991), Dyer e Singh (1998) destacam os seguintes mecanismos: (a) interconectividade dos ativos interorganizacionais; (b) escassez do parceiro; (c) indivisibilidade do recurso e; (d) ambiente institucional.

Ao levar em conta o ambiente institucional, a teoria baseada em recursos avança no sentido de, pelo menos indiretamente, considerar o papel do ambiente na formação de vantagem competitiva, o que contempla o argumento defendido por Oliver (1996), de que os impedimentos institucionais para a atividade econômica são determinantes da heterogeneidade das firmas, que se origina no ambiente institucional, portanto, estes também constituem um elemento importante para a obtenção (ou não) de vantagem competitiva. 
Na visão de Peng (2008), além da Visão Baseada na Indústria (VBI), que incorpora a análise estrutural e da Visão Baseada em Recursos (VBR), que engloba as teorias dos recursos e das capacidades dinâmicas, existe uma terceira corrente explicativa da vantagem competitiva, a Visão Baseada nas Instituições (aqui chamada de VBN), que atenta, principalmente nos países emergentes, para a força das instituições formais (leis, regulamentos, regras) e informais (normas, culturas e ética) como determinantes e/ou influenciadores no processo estratégico das organizações.

O debate acerca da gestão da cadeia de suprimento tem assumido, ao longo dos últimos anos, um papel relevante nas discussões relacionadas à gestão organizacional.

Segundo Lambert (2004), o modelo do SCM é baseado na integração dos processos-chave de negócios das empresas de uma cadeia de suprimento, sendo oito os processos de negócios essenciais: (1) Gestão do relacionamento com o cliente (CRM); (2) Gestão do serviço ao cliente (SRM); (3) Gestão da demanda; (4) Atendimento de pedidos; (5) Gestão do fluxo da manufatura; (6) Gestão do relacionamento com o fornecedor; (7) Desenvolvimento do produto $\mathrm{e}$ comercialização e; (8) Gerenciamento do retorno. Assim sendo, observa-se que o conceito e a operacionalização do SCM são relativamente complexos.

De acordo com Cousins, Lawson e Squire (2006), o SCM tem recebido elevada atenção de estudiosos de várias disciplinas acadêmicas, que têm contribuído para o aprofundamento do conhecimento e do desenvolvimento teórico desta temática. Entretanto, parece haver pouco consenso acerca das bases conceituais e de metodologia de pesquisa do SCM, o que tem contribuído para a existência de lacunas na base de conhecimento desse campo (BURGESS; SINGH; KOROGLU, 2006).

Com a intenção de avançar na construção da base conceitual de um campo de estudo é importante que os diferentes conceitos sejam agrupados em construtos. Chen e Paulraj (2004) desenvolveram um modelo de pesquisa com o objetivo de contribuir para o desenvolvimento de construtos do SCM, a partir de um conjunto inicial de medidas operacionais. Nesse modelo, o principal elemento para caracterizar o SCM é constituído pelas relações entre compradores e fornecedores que, por sua vez, podem ser representadas por cinco construtos: (i) Redução da Revista Produção Online, Florianópolis, SC, v.14, n. 4, p. 1404-1432, out./dez. 2014. 
base de fornecedores; (ii) Relações de longo prazo; (iii) Comunicação; (iv) Equipes interfuncionais e; (v) Envolvimento do fornecedor.

Pode-se perceber que, nos construtos destacados por Chen e Paulraj (2004), as competências relacionais apresentadas por Wieland e Wallenburg (2012) estão presentes. Adicionalmente, Gold, Seuring e Beske (2010) ressaltam a importância dos recursos interfirmas e competências geradas por SCM para a vantagem competitiva, bem como reforçam a pertinência do uso da "Visão Relacional" na discussão que relaciona SCM à vantagem competitiva. Segundo Barney (2012), os pressupostos da TBR suportam o argumento de que as competências heterogêneas ligadas a compras e SCM são importantes na criação de fatores estratégicos em mercados imperfeitamente competitivos, o que leva à vantagem competitiva no mercado. Nesse contexto, Brito e Berardl (2010) reforçam a necessidade do desenvolvimento de capacidade colaborativa, aprendizado e inovação.

Quando se busca compreender, entre outras questões, como a gestão da cadeia de suprimento contribui para a obtenção de vantagem competitiva, entendese que é pertinente qualificar os diferentes tipos de relacionamentos interfirmas que podem ocorrer no âmbito da cadeia de suprimento. Nesse sentido, a teoria dos custos de transação (WILLIAMSON, 1991) e a economia da governança (WILLIAMSON, 2005) trouxeram contribuições para o entendimento das vantagens e desvantagens de se estruturar as transações interfirmas de diferentes maneiras. A economia da governança faz a distinção entre três estruturas de governança básicas: mercados clássicos (trocas simples em mercados spot), estruturas híbridas (contratos de longo prazo) e hierarquias.

Ainda sobre essa questão, um argumento-chave defendido por Dyer, Cho e Chu (1998) é de que as firmas devem pensar de modo estratégico as suas relações na cadeia de suprimento, especialmente no que diz respeito à gestão de fornecedores, de modo a não ter uma estratégia única. A habilidade de uma empresa para segmentar de forma estratégica os fornecedores, de modo a obter os benefícios dos possíveis tipos de relacionamentos, provê a chave para a vantagem competitiva futura na gestão da cadeia de suprimento. Assim sendo, Dyer, Cho e Chu (1998) apresentam três possíveis regimes de relações interorganizacionais na cadeia de suprimento: regime arm's length (mercado), regime de parceria e regime de quase-mercado.

Revista Produção Online, Florianópolis, SC, v.14, n. 4, p. 1404-1432, out./dez. 2014. 
O modelo de análise desenvolvido por Viana (2010) considera um escopo ampliado da cadeia de suprimento, incluindo atores que podem influenciar o desempenho da cadeia e de suas empresas constituintes. Assim sendo, foram incluídos as instituições de fomento e o governo, de modo que as características do ambiente institucional possam ser consideradas na análise.

Além da já destacada visão de Peng (2008) acerca da força das instituições formais e informais como determinantes e ou influenciadores no processo estratégico das organizações, explicitada através da VBN, a consideração de alguns componentes do ambiente institucional na análise baseia-se em dois argumentos principais. O primeiro, sustentado por Oliver (1996), considera que as causas das ineficiências do mercado e da heterogeneidade das firmas são tanto econômicas como institucionais.

O segundo argumento, sustentado por Bandeira-de-Mello (2007a), considera que a heterogeneidade de desempenho de firmas domésticas em economias emergentes, tais como a do Brasil, e a consequente possibilidade de obtenção de vantagem competitiva, é função da efetividade dessas firmas na gestão da dependência de recursos dos stakeholders.

A Figura 1 representa modelo de análise utilizado, na qual pode ser percebido o escopo da cadeia de suprimento considerado.

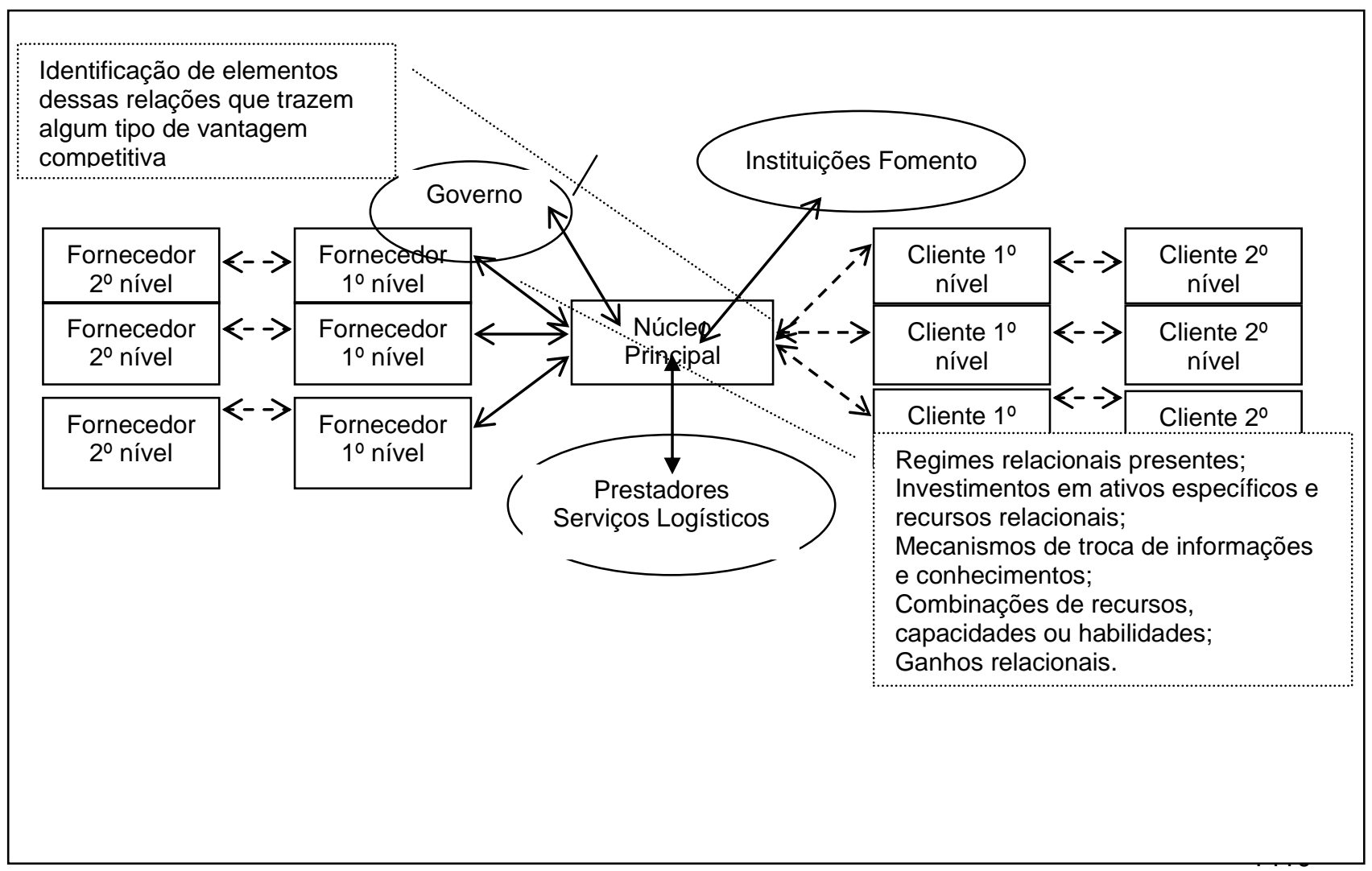


Essa visão de cadeia de suprimento é baseada no trabalho de Lambert, Cooper e Pagh (1998), que denominam o núcleo principal de "empresa focal", visão

Esta que pode ser estendida a vários níveis de fornecedores e clientes. No presente trabalho foi realizado um estudo empírico em duas empresas da indústria de calçados do Ceará, conforme será detalhado no tópico seguinte.

O foco da análise é constituído pelas relações representadas pelas setas contínuas, concentrando-se nas relações das empresas investigadas com seus principais fornecedores de matérias-primas (fornecedores de 1ํㅡivel) e prestadores de serviços logísticos, assim como na avaliação de como a empresas estabelecem relações com o governo em seus diversos níveis e com as instituições de fomento, no intuito de verificar como essas relações contribuem para a obtenção de vantagem competitiva.

De forma resumida, pode-se afirmar que o modelo proposto permite analisar os mecanismos pelos quais a gestão da cadeia de suprimento gera vantagem competitiva a partir da visão relacional, estando a análise subdividida em três níveis, conforme mostrado no Quadro 1.

Quadro 1 - Modelo de Análise

\begin{tabular}{|l|l|l|l|}
\hline Nível de Análise & \multicolumn{1}{|c|}{ Unidade de Análise } & \multicolumn{1}{|c|}{ Foco da Análise } & \multicolumn{1}{c|}{ Objetivo da Análise } \\
\hline 1. Intraorganizacional & $\begin{array}{l}\text { Firmas individuais que } \\
\text { formam o núcleo } \\
\text { principal de análise }\end{array}$ & $\begin{array}{l}\text { Recursos financeiros } \\
\text { Recursos humanos } \\
\text { Recursos tecnológicos } \\
\text { Recursos materiais } \\
\text { Recursos de } \\
\text { conhecimento }\end{array}$ & $\begin{array}{l}\text { Características dos recursos } \\
\text { Contribuição dos recursos para } \\
\text { a obtenção de rendas acima } \\
\text { do normal e a obtenção de } \\
\text { vantagem competitiva }\end{array}$ \\
\hline 2.Interorganizacional & $\begin{array}{l}\text { Relações } \\
\text { interorganizacionais das } \\
\text { firmas da cadeia de } \\
\text { suprimento e destas } \\
\text { com os prestadores de } \\
\text { serviços logísticos }\end{array}$ & $\begin{array}{l}\text { Tipos de relações } \\
\text { estabelecidas } \\
\text { Recursos relacionais }\end{array}$ & $\begin{array}{l}\text { Caracterizar os tipos de } \\
\text { relações interorganizacionais } \\
\text { Identificar investimentos em } \\
\text { ativos específicos e recursos } \\
\text { relacionais } \\
\text { Avaliar troca de informações e } \\
\text { de conhecimento, combinação } \\
\text { de recursos, capacidade e } \\
\text { habilidades nas relações } \\
\text { ldentificar ganhos relacionais e } \\
\text { mecanismos de preservação }\end{array}$ \\
& $\begin{array}{l}\text { Avaliar a influência dessas } \\
\text { relações no acesso a recursos } \\
\text { e na obtenção de vantagem } \\
\text { competitiva }\end{array}$ \\
\hline 3. Ambiente Institucional & $\begin{array}{l}\text { Relações das empresas } \\
\text { da cadeia de } \\
\text { suprimento com } \\
\text { componentes do } \\
\text { ambiente institucional }\end{array}$ & $\begin{array}{l}\text { Instituições de } \\
\text { fomento } \\
\text { Governo }\end{array}$ & \\
\hline
\end{tabular}

Fonte: Viana (2010).

Considerando o objetivo geral de investigar a contribuição da gestão da cadeia de suprimento para a obtenção de vantagem competitiva por empresas da indústria de calçados, tendo como foco principal de análise as relações Revista Produção Online, Florianópolis, SC, v.14, n. 4, p. 1404-1432, out./dez. 2014. 
interorganizacionais (díades), a análise foi restrita ao $2^{\circ}$ (interorganizacional) e ao $3^{\circ}$ (ambiente institucional) níveis de análise.

\section{PROCEDIMENTOS METODOLÓGICOS}

Tendo-se como referência os níveis de análise propostos para o presente trabalho, seus objetivos específicos e o referencial teórico, foram definidas três categorias-chave: (1) Características do relacionamento com os fornecedores; (2) Relações das empresas com o Governo e; (3) Relações das empresas com instituições de fomento.

Com relação à estratégia de pesquisa utilizada, trata-se de um estudo de caso interpretativo (GODOY, 2007) que, além de conter uma rica descrição do fenômeno estudado, busca encontrar padrões nos dados e desenvolver categorias conceituais que possibilitem ilustrar, confirmar ou oporem-se a suposições teóricas. A realização da pesquisa em mais de uma empresa configura um estudo de casos múltiplos (YIN, 2005).

Para a escolha dos casos a serem estudados, definiu-se como primeiro parâmetro a necessidade de que pertencessem a um setor industrial de relevância econômica para o estado do Ceará. A relevância econômica foi considerada em função do número de vínculos empregatícios no ano de 2010, disponível na Relação Anual de Informações Sociais - RAIS (MTE, 2011). Assim sendo, foi selecionada a indústria de calçados que, em 2010, constituiu o setor com maior número de vínculos empregatícios da indústria de transformação do Ceará, totalizando 59.127 vínculos, considerando-se a fabricação de calçados de couro e a fabricação de calçados de material sintético. Nesse setor foram escolhidas duas empresas com características diferentes em relação aos tipos de produtos que oferecem e aos segmentos de mercado em que atuam e que, além disso, estivessem disponíveis para a realização da pesquisa. As empresas pesquisadas receberam as denominações de Calçados1 e Calçados2, para preservar o seu anonimato.

Além de se fazer a pesquisa nas duas empresas que formaram o núcleo principal, investigou-se também empresas fornecedoras de matérias-primas utilizadas nos processos produtivos destas, sendo um fornecedor de cada. A inclusão dos fornecedores teve como principal função ratificar ou não as informações 
relatadas pelas empresas compradoras, o que satisfaz um requisito importante a ser seguido na coleta de dados, conforme Yin (2005): a utilização de múltiplas fontes de evidências, que constitui a técnica de triangulação dos dados.

Trata-se, portanto, de uma abordagem qualitativa. Nas pesquisas de cunho qualitativo, tanto a delimitação quanto a formulação do problema possuem características próprias, ambas exigindo do pesquisador a imersão no contexto analisado (GODOI; BALSINI, 2007).

Para a coleta dos dados primários, optou-se pela utilização de um roteiro de entrevista semiestruturado, caracterizando uma entrevista em profundidade. Foram entrevistados onze sujeitos, das empresas pesquisadas e de alguns fornecedores destas, os quais são responsáveis por conduzir os relacionamentos investigados. Cada uma das entrevistas foi gravada e, posteriormente, transcrita, para facilitar a análise de dados.

Os dados secundários foram coletados para permitir a determinação do setor e das empresas a serem pesquisados. Ademais, foram solicitados às empresas documentos escritos contendo informações relevantes das mesmas, bem como foram consultados relatórios e publicações acerca do setor de calçados.

Para proceder à análise dos dados coletados, optou-se por utilizar o método das comparações constantes (BANDEIRA-DE-MELLO; CUNHA, 2007), procedimento analítico originado da estratégia de pesquisa grounded theory (STRAUSS; CORBIN, 2008). Na verdade, tendo em vista que se partiu de teorias pré-existentes para a análise dos dados, pode-se afirmar que foram utilizados os fundamentos da adaptative theory (LAYDER, 1998), vista como representante da combinação de um moderado objetivismo com subjetivismo, de acordo com a demanda da natureza da pesquisa. Nesse caso, buscou-se a integração entre os principais aspectos que emergiram dos dados e a teoria pré-existente relatada na literatura, no sentido de avaliar a contribuição da gestão da cadeia de suprimento para a obtenção de vantagem competitiva pelas empresas pesquisadas. É importante salientar que, embora tenha sido utilizada uma abordagem de análise vinculada ao desenvolvimento de teorias a partir dos dados, o presente trabalho não se propõe a isso.

Devido à quantidade de dados a serem analisados, optou-se pela utilização do software Atlas/ti como apoio à análise, seguindo o processo de análise proposto 
por Bandeira-de-Mello (2007b), que envolve a codificação e rotulação, o desdobramento dos dados (microanálise) e o descobrimento e validação de categorias e suas relações, procedimentos de análise previstos no método das comparações constantes.

\section{ANÁLISE DOS RESULTADOS}

Para a análise dos resultados, cada uma das categorias-chave teve suas propriedades e dimensões definidas a partir do referencial teórico e, também, utilizando-se elementos que emergiram dos dados durante a análise. Para cada propriedade, verificou-se o comportamento das dimensões nas diversas citações (as quotes do Atlas/ti). Partiu-se, então, para a realização de comparações teoriaincidente e incidente-incidente (BANDEIRA-DE-MELLO; CUNHA, 2007), no intuito de identificar o comportamento das dimensões das propriedades nos dados coletados. A partir da emersão de grupos semelhantes de dimensões das propriedades em cada categoria, os mais representativos foram denominados manifestações das categorias, os quais permitiram a formatação dos esquemas gráficos que relacionam as categorias, propriedades e manifestações em cada nível de análise.

\subsection{Características do relacionamento com os fornecedores}

A categoria "características do relacionamento com os fornecedores" engloba os relacionamentos das empresas com seus fornecedores de matérias-primas e componentes, bem como os relacionamentos destas com os prestadores de serviço logístico. A caracterização desses relacionamentos atende ao primeiro objetivo específico desse artigo.

Para a análise da categoria foi definido inicialmente, a partir do referencial teórico e do modelo de análise, um total de sete propriedades e suas respectivas dimensões. Durante a análise percebeu-se a necessidade de inclusão de mais uma propriedade, "localização do fornecedor", que emergiu dos dados, ou seja, durante a análise das entrevistas a localização do fornecedor mostrou-se como importante para que se avaliem as características do relacionamento entre as empresas do 
setor de calçados e seus fornecedores. As dimensões representam as possíveis variações às quais as propriedades poderão estar sujeitas. Assim sendo, o Quadro 2 mostra o conjunto de propriedades e dimensões da categoria "características do relacionamento com os fornecedores".

Quadro 2 - Propriedades, Conceitos e Dimensões da Categoria Características do Relacionamento com o Fornecedor

\begin{tabular}{|c|c|c|c|}
\hline CATEGORIA & PROPRIEDADES & CONCEITO & DIMENSÕES \\
\hline \multirow{8}{*}{$\begin{array}{l}\text { CARACTERÍSTICAS } \\
\text { DO } \\
\text { RELACIONAMENTO } \\
\text { COM O } \\
\text { FORNECEDOR }\end{array}$} & $\begin{array}{l}\text { Orientação quanto } \\
\text { ao Prazo (ORPR) }\end{array}$ & $\begin{array}{l}\text { Tempo médio de manutenção do } \\
\text { relacionamento }\end{array}$ & $\begin{array}{l}\text { Curto (-): orientação de curto } \\
\text { prazo } \\
\text { Longo (+) orientação de } \\
\text { longo prazo }\end{array}$ \\
\hline & $\begin{array}{l}\text { Quantidade de } \\
\text { Fornecedores } \\
\text { (QUAN) }\end{array}$ & $\begin{array}{l}\text { Quantidade de fornecedores } \\
\text { para cada tipo de produto ou } \\
\text { serviço }\end{array}$ & $\begin{array}{l}\text { Pequena (-): poucos } \\
\text { fornecedores para cada } \\
\text { produto ou serviço adquirido } \\
\text { Grande }(+) \text { : muitos } \\
\text { fornecedores para cada } \\
\text { produto ou serviço adquirido }\end{array}$ \\
\hline & $\begin{array}{l}\text { Formalidade dos } \\
\text { Contratos (CONT) }\end{array}$ & $\begin{array}{l}\text { Mecanismos de regulação das } \\
\text { relações de compra e venda }\end{array}$ & $\begin{array}{l}\text { Baixa (-): ausência de } \\
\text { contratos formais } \\
\text { Alta (+): presença de } \\
\text { contratos formais }\end{array}$ \\
\hline & $\begin{array}{l}\text { Investimentos } \\
\text { Específicos para a } \\
\text { Relação (INVT) }\end{array}$ & $\begin{array}{l}\text { Investimentos duráveis em ativos } \\
\text { que são realizados em apoio a } \\
\text { transações particulares, sem } \\
\text { valor para usos alternativos } \\
\text { (WILLIAMSON, 1989) }\end{array}$ & $\begin{array}{l}\text { Baixo (-): ausência de } \\
\text { investimentos específicos; } \\
\text { Alto (+): presença de } \\
\text { investimentos específicos. }\end{array}$ \\
\hline & $\begin{array}{c}\text { Ganhos Relacionais } \\
\text { (GARL) }\end{array}$ & $\begin{array}{l}\text { Ganhos acima da média do } \\
\text { mercado que só podem ser } \\
\text { gerados através de contribuições } \\
\text { idiossincráticas conjuntas dos } \\
\text { parceiros de uma relação } \\
\text { (DYER; SINGH, 1998) }\end{array}$ & $\begin{array}{l}\text { Baixo (-): o relacionamento } \\
\text { não apresenta ganhos } \\
\text { relacionais } \\
\text { Alto (+): o relacionamento } \\
\text { apresenta ganhos relacionais }\end{array}$ \\
\hline & $\begin{array}{c}\text { Troca de } \\
\text { Informações (TINF) }\end{array}$ & $\begin{array}{l}\text { Avaliação dos tipos de } \\
\text { informações trocadas e sua } \\
\text { importância para o } \\
\text { relacionamento }\end{array}$ & $\begin{array}{l}\text { Pequena (-): quando há } \\
\text { pouca ou nenhuma troca de } \\
\text { informações } \\
\text { Grande (+): quando há } \\
\text { intensa e frequente troca de } \\
\text { informações }\end{array}$ \\
\hline & $\begin{array}{l}\text { Troca de } \\
\text { Conhecimentos } \\
\text { (TCON) }\end{array}$ & $\begin{array}{l}\text { Os relacionamentos podem } \\
\text { contemplar troca de } \\
\text { conhecimentos através da } \\
\text { participação do fornecedor em } \\
\text { processos do comprador e vice- } \\
\text { versa }\end{array}$ & $\begin{array}{l}\text { Pequena (-): ausência de } \\
\text { troca de conhecimentos } \\
\text { Grande }(+) \text { : presença de } \\
\text { troca de conhecimentos }\end{array}$ \\
\hline & $\begin{array}{l}\text { Localização do } \\
\text { Fornecedor (LOCL) }\end{array}$ & $\begin{array}{l}\text { Distância das instalações do } \\
\text { fornecedor em relação às } \\
\text { instalações produtivas da } \\
\text { empresa compradora }\end{array}$ & $\begin{array}{l}\text { Perto (-): o fornecedor possui } \\
\text { instalações nas proximidades } \\
\text { da empresa; } \\
\text { Longe (+): o fornecedor não } \\
\text { possui instalações nas } \\
\text { proximidades da empresa }\end{array}$ \\
\hline
\end{tabular}

Fonte: Elaboração dos autores

As comparações constantes realizadas entre os incidentes obtidos nas entrevistas transcritas revelaram comportamentos semelhantes das oito propriedades ao longo de suas dimensões. Esses comportamentos semelhantes Revista Produção Online, Florianópolis, SC, v.14, n. 4, p. 1404-1432, out./dez. 2014. 
foram associados a um mesmo código. Um código cuja ocorrência foi consistente e repetida foi considerado uma manifestação, sendo que cada manifestação pode estar relacionada com mais de uma propriedade. No total, foram identificadas sete manifestações da categoria características do relacionamento com o fornecedor, as quais são apresentadas no Quadro 3, que indica, também, o comportamento das dimensões (+/-) das propriedades em cada manifestação.

Quadro 3 - Dimensões das Propriedades e Manifestações da Categoria Características do Relacionamento com o Fornecedor

\begin{tabular}{|l|c|c|c|c|c|c|c|c|}
\hline \multicolumn{1}{|c|}{ MANIFESTAÇÕES } & \multicolumn{7}{|c|}{ DIMENSÕES DAS PROPRIEDADES } \\
\cline { 2 - 9 } & ORPR & QUAN & CONT & INVS & GARL & TINF & TCON & LOCL \\
\hline $\begin{array}{l}\text { Investimentos específicos } \\
\text { dos fornecedores }\end{array}$ & + & - & - & + & + & & & - \\
\hline $\begin{array}{l}\text { Ganhos com a } \\
\text { proximidade do fornecedor }\end{array}$ & & & & + & + & & & - \\
\hline $\begin{array}{l}\text { Relacionamento de longo } \\
\text { prazo }\end{array}$ & + & - & - & & & & & \\
\hline $\begin{array}{l}\text { Desenvolvimento conjunto } \\
\text { de materiais e produtos }\end{array}$ & + & - & - & & & + & + & \\
\hline $\begin{array}{l}\text { Troca eletrônica de } \\
\text { informações }\end{array}$ & + & & & & & + & & \\
\hline $\begin{array}{l}\text { Ausência de contratos } \\
\text { formais }\end{array}$ & & - & - & & & & & \\
\hline $\begin{array}{l}\text { Poucos fornecedores por } \\
\text { item }\end{array}$ & & - & & & & & & \\
\hline
\end{tabular}

Fonte: Elaboração dos Autores

A manifestação denominada investimentos específicos dos fornecedores ocorreu para os fornecedores de tintas, pigmentos e para a gráfica, no caso da Calçados1, bem como para os fornecedores de solados, palmilhas e saltos e aquele que executa a costura dos componentes, no caso da Calçados2. Na ocorrência de investimentos específicos dos fornecedores, há fornecimento praticamente exclusivo dos insumos por parte destes (QUAN-), foram identificados ganhos relacionais (GARL+) e, geralmente, os investimentos específicos foram relacionados à instalação de plantas dos fornecedores no estado do Ceará (LOCL-).

Os ganhos com a proximidade do fornecedor foram percebidos como ganhos relacionais (GARL+), diretamente ligados aos investimentos específicos dos fornecedores (INVS+; LOCL-). O relacionamento de longo prazo constitui uma manifestação de todas as relações das empresas com os fornecedores de matériasprimas e componentes. 
O desenvolvimento conjunto de materiais e produtos se dá com alguns fornecedores de materiais e componentes, nos quais há uma intensa e frequente troca de informações (TINF+), bem como uma troca de conhecimentos (TCON+), a partir do compartilhamento de recursos, capacidades e competências. A troca eletrônica de informações é bastante utilizada pelas empresas no relacionamento com seus fornecedores, com o uso do EDI (Electronic Data Interchange), que constitui um link eletrônico exclusivo entre os computadores de compradores e vendedores (BALLOU, 2006). Ademais, um total de trinta e nove fornecedores é responsável pelo gerenciamento dos estoques das matérias-primas da empresa Calçados1, através da ferramenta VMI (Vendor Management Inventory). Segundo Chopra e Meindl (2004), com o uso do VMI, os fornecedores ficam responsáveis por todas as decisões acerca dos estoques de produtos do comprador, assumindo o controle da decisão de ressuprimento, desde que tenham acesso às informações sobre a demanda dos produtos dos compradores.

Destacou-se, também, a ausência de contratos formais (CONT-) em todos os relacionamentos com os fornecedores de matérias-primas e componentes das duas empresas, nos quais a confiança emergiu como um importante mecanismo de governança. Por fim, conforme já mencionado, predomina nas relações das empresas com seus fornecedores uma pequena quantidade de fornecedores (QUANT-) por item (até três fornecedores), sendo que, para algumas matériasprimas, os fornecedores são exclusivos.

A ocorrência concomitante das manifestações "ausência de contratos formais" e "presença de investimentos específicos" corrobora o argumento de Dyer e Singh (1998), de que os investimentos específicos podem ser fontes de ganhos relacionais com o uso de mecanismos de governança mais efetivos do que os contratos e, consequentemente, menores custos de transação.

As propriedades da categoria características do relacionamento com o fornecedor, suas manifestações e respectivos graus de fundamentação empírica (groundedness), densidade teórica (density) e exemplos (quotes) de cada uma das manifestações são apresentados na Figura 2, que constitui uma network gerada com o uso do Atlas/ti. Na referida figura, os retângulos maiores representam os códigos, que podem ser categorias (iniciam com C:), propriedades (iniciam com P:) ou manifestações (iniciam com $\mathrm{M}$ :). Os números nos formatos (a:b) representam 
citações (quotes) ou trechos das entrevistas em que ocorreram as manifestações com as quais se relacionam.

Figura 2 - Esquema Gráfico das Propriedades, Manifestações, Fundamentação Empírica e Densidade Teórica da Categoria Características do Relacionamento com o Fornecedor

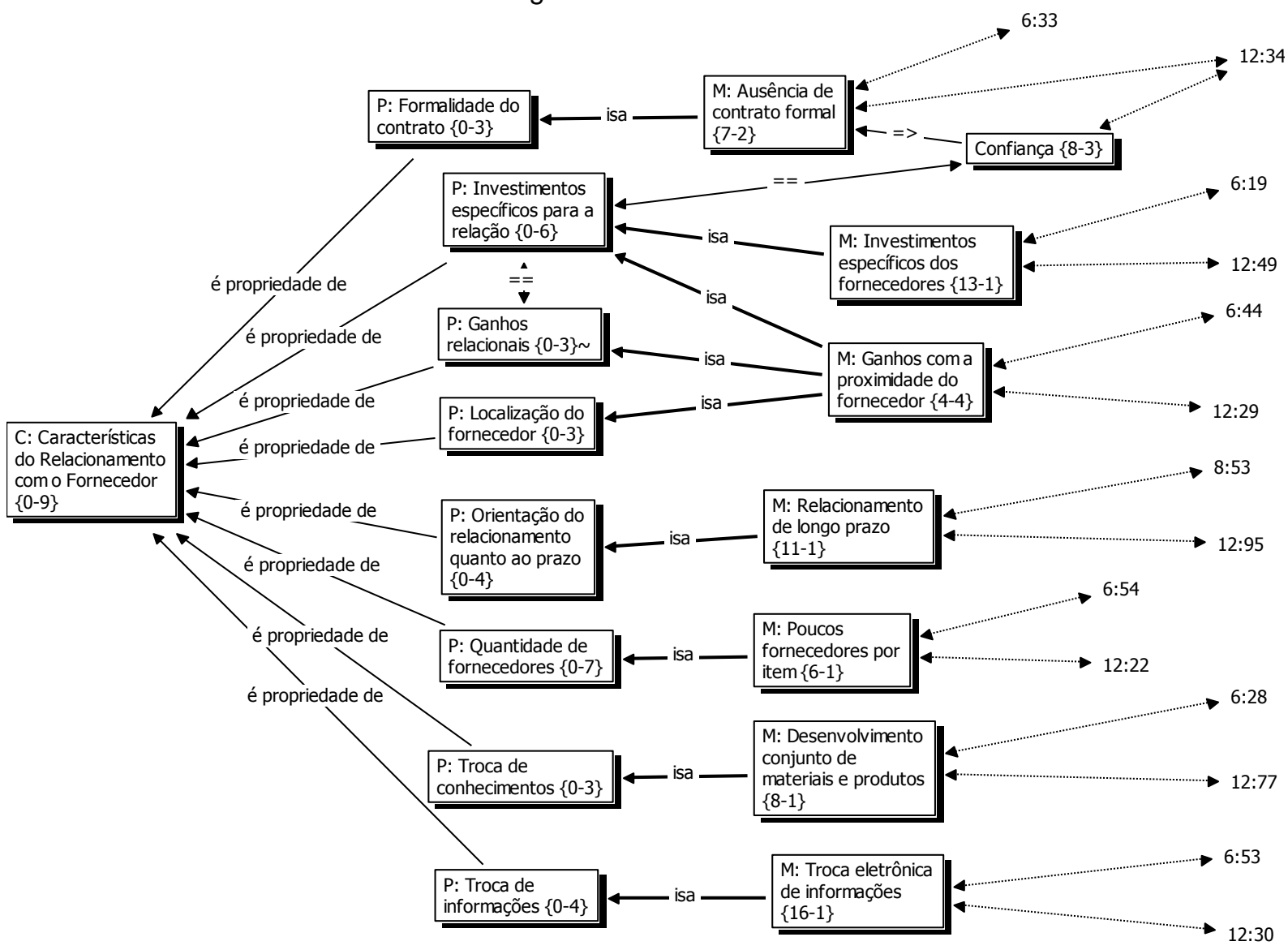

Fonte: Elaboração dos Autores.

A Figura 2 suscita alguns comentários adicionais. Em linhas gerais, os relacionamentos das empresas Calçados1 e Calçados2 com seus fornecedores podem ser caracterizados por não possuírem contratos formais para governá-los, o que é possível devido à existência de confiança entre as partes que formam os relacionamentos, ou seja, a confiança é um dos fatores que "causam" a não existência de contratos formais. Considera-se no presente trabalho o conceito de confiança adotado por Barney e Hansen (1994), como uma crença mútua de que nenhum dos participantes de uma transação explorará as vulnerabilidades do outro. Além disso, a confiança está diretamente relacionada à ocorrência de investimentos específicos (WILLIAMSON, 1991) por parte de alguns desses fornecedores, fato condizente com os achados de Johnston et al. (2004), de que maiores níveis de 
confiança na empresa compradora levam os fornecedores a um maior envolvimento em comportamentos cooperativos, que facilitam um melhor desempenho de ambos.

Da mesma forma, Gold, Seuring e Beske (2010) consideram a confiança um recurso relacional valioso, que não pode ser comercializado no mercado e é difícil de imitação por parte dos concorrentes, contribuindo para a vantagem competitiva e constituindo um pré-requisito para que os membros de uma cadeia de suprimento engajem-se em práticas colaborativas. A confiança facilita o comprometimento de todos os atores da cadeia de suprimento, funcionando como um catalisador para a transferência de conhecimento e os processos de aprendizagem interfirmas, elementos essenciais para a capacidade de inovação das empresas pesquisadas.

Os investimentos específicos que, no geral, constituem investimentos na instalação de plantas industriais de alguns fornecedores no estado do Ceará, para propiciar um melhor atendimento às empresas Calçados1 e Calçados2, contribuem para a ocorrência de ganhos relacionais. Ou seja, o fato de existirem instalações produtivas dos fornecedores localizadas no estado do Ceará traz os chamados ganhos com a proximidade do fornecedor, que constituem ganhos relacionais, entre os quais podem ser destacados: ganhos fiscais, diminuição dos lead times, menores custos logísticos e menores custos de produção.

Ademais, percebe-se que as empresas procuram manter poucos fornecedores por item, estabelecendo relacionamentos de longo prazo com a maioria dos fornecedores, utilizando comumente ferramentas de tecnologia da informação para subsidiar a troca de informações.

Por fim, existe uma intensa troca de conhecimentos das empresas com seus fornecedores de matérias-primas e componentes durante o processo de desenvolvimento de materiais e produtos, através da combinação de recursos, capacidades e competências, o que contribui para que as empresas possuam grande capacidade de inovação, atributo fundamental para um setor produtivo vinculado à moda, como o setor de calçados.

A troca de conhecimentos ocorre através da participação direta dos fornecedores no processo de criação e desenvolvimento de materiais e produtos, gerando aprendizagem conjunta, geração de novos conhecimentos e inovação, elementos estes que, na visão de Chen, Lin e Chang (2009), Gold, Seuring e Beske 
(2010) e Brito e Berardl (2010), são fundamentais para a vantagem competitiva relacional.

É importante ressaltar que as duas empresas pesquisadas, considerando-se suas unidades fabris localizadas no Ceará, concorrem com produtos diferentes em mercados-alvo diferentes: a empresa Calçados1 fabrica predominantemente calçados plásticos, tendo o PVC como principal matéria-prima, voltados principalmente para o mercado interno, enquanto que a empresa Calçados2 fabrica em suas unidades do Ceará calçados de couro, com alto valor agregado, voltados para a exportação, a partir da encomenda de grandes redes varejistas da Europa e dos Estados Unidos. Apesar dessas diferenças significativas, os relacionamentos das empresas com seus fornecedores apresentam similaridades.

No que diz respeito à percepção das empresas acerca da contribuição dos relacionamentos com os fornecedores para a vantagem competitiva, há um entendimento de que existem diversas vantagens, diretamente associadas aos ganhos relacionais. Para a empresa Calçados1, os relacionamentos contribuem, também, para que a empresa possa manter-se sempre na busca de inovações de produtos que, juntamente com o marketing associado às marcas que a empresa detém a concessão de uso, pode constituir outra fonte de vantagem competitiva. Já no caso da Calçados2, os relacionamentos possibilitam a atuação da empresa de forma competitiva no negócio para as quais estão voltadas suas instalações produtivas do Ceará, que é a exportação de calçados femininos de alto valor agregado.

Conforme previsto, foram pesquisados também dois fornecedores do setor de calçados, sendo um de cada empresa, para complementar e dar maior confiabilidade aos dados relativos aos relacionamentos investigados, de modo a satisfazer ao procedimento de triangulação dos dados. Em linhas gerais, foram confirmadas pelos fornecedores as informações relatadas pela Calçados1 e pela Calçados2.

Essas características dos relacionamentos das empresas com seus fornecedores permitem que se conclua que há a predominância da estrutura de governança híbrida (WILLIAMSON, 1991) e do regime relacional de parceria (DYER; $\mathrm{CHO}$; CHU, 1998). Ademais, foram observadas as seguintes características que configuram a ocorrência dos pressupostos da gestão da cadeia de suprimento, conforme a visão de Chen e Paulraj (2004): uso intensivo de tecnologia da Revista Produção Online, Florianópolis, SC, v.14, n. 4, p. 1404-1432, out./dez. 2014. 
informação, redução da base de fornecimento, fluxos de comunicação e interação nos dois sentidos entre compradores e fornecedores, envolvimento do fornecedor em processos do comprador e possibilidade de integração logística. Por fim, pode-se afirmar que as características supracitadas contribuem para a obtenção de vantagem competitiva por parte das empresas pesquisadas.

A caracterização estabelecida contempla o atendimento ao primeiro objetivo específico desse trabalho, propiciado pela utilização do modelo de análise anteriormente detalhado. A partir dessas considerações, pode-se fazer a seguinte afirmação:

\section{A1: Nas relações das empresas pesquisadas do setor de calçados com seus fornecedores há a predominância do regime de parceria e são aplicados os principais pressupostos da gestão da cadeia de suprimento, o que contribui para a obtenção de vantagem competitiva relacional.}

\subsection{Relações das empresas com o Governo}

A segunda categoria-chave do trabalho foi analisada com foco no objetivo do estabelecimento das relações e na avaliação da influência destas no acesso a recursos e na obtenção de vantagem competitiva, que contribui para o atendimento ao segundo objetivo específico do trabalho.

É importante ressaltar que ambas as empresas, originalmente, não possuíam instalações produtivas no estado do Ceará, apenas no Rio Grande do Sul, seu estado de origem. A Calçados1 seguiu uma trajetória de transferência do seu locus de produção, iniciando sua produção no Ceará em 1990. Já a Calçados2 transferiu parte de sua produção para o Ceará, para atender ao mercado externo no segmento de calçados femininos de couro de alto valor agregado. Nesse contexto, a atuação do Governo se mostrou fundamental para a consolidação desse processo.

De acordo com os entrevistados, a vinda da Calçados1 para o Nordeste, especificamente para o estado do Ceará, não se tratou de uma opção, mas de uma necessidade, para que fosse possível a sobrevivência da empresa em termos competitivos. Aparentemente, a disponibilidade de mão de obra para a produção de calçados, com custo relativamente abaixo, soma-se aos incentivos fiscais como 
importante fator de atratividade para a instalação de empresas calçadistas no Nordeste e, particularmente, no Ceará, corroborando com a visão de Diniz e Basques (2004), de que, em função do quadro estrutural relacionado aos fatores macroeconômicos no início da década de 1990, bem como do grande potencial de expansão do mercado interno de calçados populares (plástico), iniciou-se o processo de transferência ou construção de novas unidades produtoras no Nordeste por grandes grupos calçadistas de São Paulo e do Rio Grande do Sul, estimulado e determinado pela existência de incentivos fiscais e do menor custo do trabalho na Região.

No caso da Calçados2, a implantação sequencial de três unidades fabris no Ceará também buscava aproveitar o menor custo da mão de obra e os incentivos fiscais. Entretanto, pode-se acrescentar um terceiro fator de atratividade, que é a localização geográfica do Estado em relação aos Estados Unidos e à Europa, localidades onde estão situados os clientes atendidos pelas unidades produtivas da empresa que estão no Ceará, tendo em vista que a produção dessas unidades é destinada exclusivamente à exportação.

Para a categoria relações das empresas com o Governo, foram definidas as propriedades e dimensões apresentadas no Quadro 4.

Quadro 4 - Propriedades, Conceitos e Dimensões da Categoria Relações das Empresas com o

\begin{tabular}{|c|c|c|c|}
\hline CATF & & & \\
\hline \multirow{3}{*}{$\begin{array}{l}\text { RELAÇÕES } \\
\text { DAS } \\
\text { EMPRESAS } \\
\text { COM O } \\
\text { GOVERNO }\end{array}$} & $\begin{array}{l}\text { Objetivos das } \\
\text { relações (OBRL) }\end{array}$ & $\begin{array}{l}\text { Quais os diferentes objetivos } \\
\text { da empresa ao se relacionar } \\
\text { com o governo }\end{array}$ & $\begin{array}{l}\text { Poucos (-): poucos } \\
\text { objetivos diferentes } \\
\text { Muitos (+): muitos objetivos } \\
\text { diferentes }\end{array}$ \\
\hline & $\begin{array}{c}\text { Influência das } \\
\text { relações na } \\
\text { vantagem competitiva } \\
\text { (IRVC) }\end{array}$ & $\begin{array}{l}\text { Percepção da empresa acerca } \\
\text { da influência das relações com } \\
\text { o Governo na obtenção de } \\
\text { vantagem competitiva }\end{array}$ & $\begin{array}{l}\text { Baixa (-): baixa influência } \\
\text { das relações na obtenção } \\
\text { de vantagem competitiva } \\
\text { Alta }(+) \text { : alta influência das } \\
\text { relações na obtenção de } \\
\text { vantagem competitiva }\end{array}$ \\
\hline & $\begin{array}{l}\text { Forma de estabelecer } \\
\text { a relação (FERL) }\end{array}$ & $\begin{array}{l}\text { Se a relação é estabelecida de } \\
\text { forma isolada pela empresa ou } \\
\text { em conjunto com outras } \\
\text { empresas ou entidades }\end{array}$ & $\begin{array}{l}\text { Isolada (-): a empresa } \\
\text { estabelece as relações } \\
\text { individualmente } \\
\text { Em conjunto (+): a } \\
\text { empresa estabelece as } \\
\text { relações em conjunto com } \\
\text { outras empresas ou } \\
\text { entidades }\end{array}$ \\
\hline
\end{tabular}

Fonte: Elaboração dos Autores. 
As comparações constantes realizadas entre os incidentes obtidos nas entrevistas transcritas revelaram quatro manifestações mais consistentes das dimensões das propriedades da categoria (Quadro 5).

Quadro 5 - Dimensões das Propriedades e Manifestações da Categoria Relações das Empresas com o Governo

\begin{tabular}{|l|c|c|c|}
\hline \multirow{2}{*}{\multicolumn{1}{|c|}{ MANIFESTAÇÕES }} & \multicolumn{3}{c|}{ DIMENSÕES DAS PROPRIEDADES } \\
\cline { 2 - 4 } & OBRL & IRVC & FERL \\
\hline Incentivos fiscais & - &,+- & - \\
\hline $\begin{array}{l}\text { Vantagem em relação a empresas } \\
\text { que não estão no Nordeste }\end{array}$ & & + & \\
\hline Paridade competitiva & &,+- & \\
\hline Relações isoladas & & & - \\
\hline
\end{tabular}

Fonte: Elaboração dos autores.

Em linhas gerais, as empresas buscam estabelecer relações com o Governo, principalmente nos níveis federal e estadual, para a obtenção e manutenção de incentivos fiscais, de variados tipos. Assim sendo, os objetivos do estabelecimento das relações são pouco variados. O principal recurso que as empresas têm acesso ao se relacionarem com o Governo, em seus diversos níveis, é o incentivo fiscal, seja este a redução da alíquota do ICMS, o crédito de $11 \%$ do valor FOB das exportações, ou a redução do montante pago de IRPJ (redução do valor pago em $75 \%$ ). Considerando o incentivo fiscal como um recurso, torna-se relevante avaliar suas características a partir do modelo VRIO (BARNEY; HESTERLY, 2007), para verificar sua possível contribuição para a vantagem competitiva: (1) trata-se de um recurso valioso, já que traz ganhos financeiros importantes para a manutenção da posição competitiva das empresas; (2) não é raro, já que várias empresas do setor de calçados possuem incentivos semelhantes àqueles obtidos pela Calçados1 e pela Calçados2, pelo fato de possuírem instalações produtivas no Nordeste; (3) não é difícil de imitar (a obtenção do recurso), pois, teoricamente, qualquer empresa do setor de calçados que se enquadre nas características exigidas pelos governos, ao se instalar no Nordeste, pode pleitear incentivos fiscais; (4) as empresas estão preparadas para buscar e utilizar os incentivos.

Considerando-se o exposto, pode-se concluir que os incentivos fiscais têm como consequência uma vantagem competitiva temporária das duas empresas em relação aos seus concorrentes que não possuem instalações produtivas no Nordeste, que perdurará até que o façam; além disso, levam a uma situação de Revista Produção Online, Florianópolis, SC, v.14, n. 4, p. 1404-1432, out./dez. 2014. 
paridade competitiva em relação aos concorrentes que possuem plantas industriais no Nordeste. Por fim, no que diz respeito à forma como as empresas estabelecem as relações com o Governo, prevaleceu a manifestação denominada relações isoladas, ou seja, na maior parte das situações, as empresas buscam a obtenção e manutenção dos incentivos, ao se relacionarem com o Governo, de forma isolada.

A partir das considerações supracitadas, pode-se fazer a seguinte afirmação:

A2: As relações das empresas pesquisadas do setor de calçados com 0 governo, que permitem o acesso a incentivos fiscais, contribuem para a obtenção de vantagem competitiva temporária em relação aos concorrentes que não possuem instalações produtivas no Nordeste, bem como levam à situação de paridade competitiva em relação aos concorrentes que possuem instalações produtivas no Nordeste a aos concorrentes no mercado externo.

\subsection{Relações das empresas com instituições de fomento}

A terceira categoria-chave do trabalho foi analisada de modo semelhante à segunda, já que ambas estão inseridas no ambiente institucional. Durante a análise, a intenção era de se trabalhar com as mesmas propriedades da categoria relações das empresas com o governo, entretanto, não se viu sentido em trabalhar com a propriedade "forma de estabelecer a relação", já que, de antemão, já se sabia que as empresas fazem isso de forma individual. Desse modo, foram definidas para essa categoria as propriedades e dimensões apresentadas no Quadro 6.

Quadro 6 - Propriedades, Conceitos e Dimensões da Categoria Relações das Empresas com Instituições de Fomento

\begin{tabular}{|c|c|c|c|}
\hline CATEGORIA & PROPRIEDADES & CONCEITO & DIMENSÕES \\
\hline \multirow{2}{*}{$\begin{array}{l}\text { RELAÇÕES } \\
\text { DA EMPRESA } \\
\text { COM } \\
\text { INSTITUIÇÕES } \\
\text { DE FOMENTO }\end{array}$} & $\begin{array}{l}\text { Objetivos das } \\
\text { relações (OBRL) }\end{array}$ & $\begin{array}{l}\text { Quais os diferentes objetivos } \\
\text { da empresa ao se relacionar } \\
\text { com as instituições de } \\
\text { fomento }\end{array}$ & $\begin{array}{l}\text { Poucos (-): poucos } \\
\text { objetivos diferentes } \\
\text { Muitos (+): muitos } \\
\text { objetivos diferentes }\end{array}$ \\
\hline & $\begin{array}{l}\text { Influência das } \\
\text { relações na } \\
\text { vantagem } \\
\text { competitiva (IRVC) }\end{array}$ & $\begin{array}{l}\text { Percepção da empresa } \\
\text { acerca da influência das } \\
\text { relações com as instituições } \\
\text { de fomento na obtenção de } \\
\text { vantagem competitiva }\end{array}$ & $\begin{array}{l}\text { Baixa (-): baixa influência } \\
\text { das relações na obtenção } \\
\text { de vantagem competitiva } \\
\text { Alta (+): alta influência } \\
\text { das relações na obtenção } \\
\text { de vantagem competitiva }\end{array}$ \\
\hline
\end{tabular}

Fonte: Elaboração dos Autores.

As comparações constantes realizadas entre os incidentes obtidos nas entrevistas transcritas revelaram quatro manifestações (Quadro 7).

Revista Produção Online, Florianópolis, SC, v.14, n. 4, p. 1404-1432, out./dez. 2014. 
Quadro 7 - Dimensões das Propriedades e Manifestações da Categoria Relações da Empresa com Instituições de Fomento

\begin{tabular}{|l|c|c|}
\hline \multirow{2}{*}{\multicolumn{1}{|c|}{ MANIFESTAÇÕES }} & \multicolumn{2}{c|}{ DIMENSÕES DAS PROPRIEDADES } \\
\cline { 2 - 3 } & OBRL & IRVC \\
\hline Obtenção de incentivos fiscais & - &,+- \\
\hline Obtenção de recursos financeiros & - &,+- \\
\hline $\begin{array}{l}\text { Vantagem em relação a empresas } \\
\text { que não estão no Nordeste }\end{array}$ & & + \\
\hline Paridade competitiva & &,+- \\
\hline
\end{tabular}

Fonte: Elaboração dos Autores.

As empresas buscam estabelecer relações com instituições de fomento com dois objetivos principais: a obtenção de incentivos fiscais, quando a relação envolve as empresas e a Superintendência de Desenvolvimento do Nordeste (SUDENE), órgão do Governo Federal que tem a missão de fomentar o desenvolvimento do Nordeste, através de diversos instrumentos, entre os quais se destaca a isenção de $75 \%$ do valor a pagar de IRPJ para empresas que investem em projetos industriais na Região e; a obtenção de recursos financeiros, obviamente, junto aos bancos, para diferentes finalidades. Como os objetivos do estabelecimento das relações das empresas com as instituições de fomento se resumem basicamente a esses dois, considerou-se que, em ambas as manifestações, a dimensão se configurou como poucos objetivos diferentes (sinal negativo).

O comportamento dessas duas manifestações em relação à influência das relações na vantagem competitiva também é semelhante, tendo sido considerado com influência moderada, pois podem levar às situações de vantagem competitiva, quando os concorrentes não possuem instalações produtivas no Nordeste, ou paridade competitiva, em relação aos concorrentes que também se localizam no Nordeste e aos concorrentes internacionais. Dessa forma, as manifestações da percepção das empresas acerca da influência das relações com as instituições de fomento na obtenção de vantagem competitiva foram duas. A primeira, denominada vantagem em relação a empresas que não estão no Nordeste, apresenta uma alta influência das relações na vantagem competitiva, embora esteja relacionada a uma vantagem competitiva temporária; já a segunda, denominada paridade competitiva, apresenta uma influência moderada das relações na vantagem competitiva, pois não traz vantagem competitiva, mas, por outro lado, não expõe as empresas a uma situação de desvantagem competitiva. 
Um fator relevante dessas manifestações é que, quando a relação das empresas se dá com os bancos, com o objetivo de obter recursos financeiros, foi destacado o papel do Banco do Nordeste, que opera o Fundo Constitucional de Financiamento do Nordeste (FNE), com taxas bastante atrativas no cenário do mercado financeiro brasileiro.

Tendo como foco o recurso financeiro obtido através das relações com as instituições de fomento, torna-se relevante, também, avaliá-lo com o uso do modelo VRIO, para verificar sua possível contribuição para a vantagem competitiva: (1) tratase de um recurso valioso, já que permite às empresas a realização dos investimentos necessários para a manutenção das suas posições competitivas em seus mercados de atuação; (2) não é raro, já que várias empresas do setor de calçados podem acessar o recurso nas mesmas condições, pelo fato de possuírem instalações produtivas no Nordeste; (3) não é difícil de imitar (a obtenção do recurso), pois, teoricamente, qualquer empresa do setor de calçados que se enquadre nas características exigidas pelas instituições de fomento, ao se instalar no Nordeste, pode pleitear a obtenção do recurso financeiro nas mesmas condições; (4) as empresas estão organizadas para a exploração do recurso.

Considerando-se essas características do recurso financeiro, confirmam-se as situações de vantagem competitiva temporária em relação às empresas que não estão no Nordeste, bem como de paridade competitiva em relação aos concorrentes que também possuem instalações no Nordeste ou que são concorrentes internacionais. A partir das considerações supracitadas, pode-se fazer a seguinte afirmação:

A3: As relações das empresas pesquisadas do setor de calçados com as instituições de fomento, que permitem o acesso a incentivos fiscais e a recursos financeiros a taxas de juros atrativas, contribuem para a obtenção de vantagem competitiva temporária em relação aos concorrentes que não possuem instalações produtivas no Nordeste, bem como levam à situação de paridade competitiva em relação aos concorrentes que possuem instalações produtivas no Nordeste a aos concorrentes no mercado externo. 


\section{CONCLUSÕES}

Esse artigo investigou a contribuição da gestão da cadeia de suprimento para a obtenção de vantagem competitiva por duas empresas da indústria de calçados do Ceará, utilizando como referência o modelo de análise desenvolvido por Viana (2010). Com o auxílio do software Atlas/ti, foram analisadas as três categorias-chave do trabalho: características do relacionamento com o fornecedor, relações das empresas com o Governo e relações das empresas com instituições de fomento.

Para a categoria características do relacionamento com o fornecedor, cuja análise permitiu o atendimento do primeiro objetivo específico do trabalho, as manifestações de suas propriedades foram condizentes com os construtos da gestão da cadeia de suprimento (CHEN; PAURAJ, 2004): reduzida base de fornecedores (poucos fornecedores); relações de longo prazo (relacionamento de longo prazo); comunicação (troca eletrônica de informações); equipes interfuncionais e envolvimento do fornecedor (desenvolvimento conjunto de materiais e produtos). Ademais, observou-se a ocorrência de investimentos específicos (WILLIAMSON, 1991) dos fornecedores para a relação, com a instalação de unidades produtivas no estado do Ceará, não são utilizados contratos formais para governar as relações e foram identificados ganhos relacionais (DYER; SINGH, 1998) associados aos relacionamentos.

Considerando-se o exposto, pode-se afirmar que, para as empresas analisadas, a gestão da cadeia de suprimento contribui para a obtenção de vantagem competitiva baseada em recursos relacionais.

A análise das duas outras categorias permitiu o atendimento do segundo objetivo específico do trabalho. Para a categoria relações das empresas com o Governo, as manifestações de suas propriedades permitem relatar que, em linhas gerais, as empresas estabelecem suas relações com o Governo de forma isolada, com o intuito de obter incentivos fiscais. Considerando-se o incentivo fiscal como um recurso, pode-se afirmar que este contribui para a obtenção de vantagem competitiva (temporária) em relação aos concorrentes das empresas que não possuem instalações produtivas no Nordeste, bem como paridade competitiva em relação àqueles concorrentes que também possuem fábricas na Região. 
No caso da terceira categoria-chave, relações das empresas com instituições de fomento, as manifestações de suas propriedades permitem afirmar que as empresas mantêm relações com instituições de fomento na busca por obter recursos financeiros e incentivos fiscais. A contribuição dos recursos financeiros para a obtenção de vantagem competitiva é semelhante à dos incentivos fiscais, ou seja, leva as empresas a uma situação de vantagem competitiva temporária em relação aos concorrentes que não atuam no Nordeste e a uma situação de paridade competitiva em relação àqueles que possuem instalações produtivas na Região.

Pode-se destacar como principal contribuição teórica deste artigo a aplicação da teoria baseada em recursos para o entendimento de como as relações e a gestão da cadeia de suprimento podem contribuir para a obtenção de vantagem competitiva, incorporando novos elementos e fortalecendo o "núcleo" do campo de conhecimento do SCM.

Apesar de os achados deste trabalho terem preenchido algumas lacunas do conhecimento relacionado à contribuição do SCM para a obtenção de vantagem competitiva, percebe-se que esses mesmos achados podem ser investigados com maior profundidade, através da realização de novas pesquisas. Primeiramente, em linhas gerais, pode-se considerar que as três afirmações efetuadas (A1, A2 e A3) na seção 4, as quais não podem ter uma generalização estatística, poderiam ser utilizadas como hipóteses a serem testadas em trabalhos de cunho quantitativo, em uma quantidade de empresas que representem uma amostra significativa dentro de cada setor estudado.

No que diz respeito ao escopo da cadeia de suprimento considerado para a realização do presente estudo, o qual é apresentado no modelo de análise, percebese que este inclui fornecedores de $1^{\circ}$ e $2^{2}$ níveis, assim como clientes de $1^{\circ}$ e $2^{\circ}$ níveis. Entretanto, optou-se no presente estudo por incluir apenas os fornecedores de $1^{\circ}$ nível. Sabendo-se da dificuldade em realizar estudos que envolvam fornecedores e clientes de $2^{\circ}$ nível, poder-se-ia, ao menos, envolver também os clientes de $1^{\circ}$ nível em estudos futuros ligados à gestão da cadeia de suprimento. No setor de calçados, considerando-se a indústria de calçados como núcleo principal de análise, isso incluiria o varejo, que constitui um agente fundamental na definição dos tipos de produtos a serem lançados, dos tipos de materiais a serem utilizados, dos lead times envolvidos, entre outros aspectos. Ainda com relação ao modelo de 
análise, estudos futuros poderiam também envolver uma investigação mais detalhada do papel dos recursos internos (nível de análise intraorganizacional) na obtenção de vantagem competitiva por parte das empresas.

\section{REFERÊNCIAS}

ACEDO, F. J.; BARROSO, C.; GALAN, J. L. The resource-based theory: dissemination and main trends. Strategic Management Journal, v. 27, p. 621-636, 2006. http://dx.doi.org/10.1002/smj.532

BALLOU, R. H. Gerenciamento da cadeia de suprimentos/Logística empresarial. 5. ed. Porto Alegre: Bookman, 2006

BANDEIRA-DE-MELLO, R. External dependencies, relational resources and performance heterogeneity in emerging economies. In: ENCONTRO DA ASSOCIAÇÃO NACIONAL DE PÓS-GRADUAÇÃO EM ADMINISTRAÇÃO, 31, 2007, Rio de Janeiro. Anais... Rio de Janeiro: ANPAD, 2007a.

BANDEIRA-DE-MELLO, R. Softwares em pesquisa qualitativa. In: SILVA, A. B. da; GODOI, C. K.; BANDEIRA-DE-MELLO, R; Pesquisa qualitativa em estudos organizacionais. São Paulo: Saraiva, cap. 15, p. 429-460, 2007 b.

BANDEIRA-DE-MELLO, R.; CUNHA, C. J. C. de A. Grounded Theory. In: SILVA, A. B. da; GODOI, C. K.; BANDEIRA-DE-MELLO, R; Pesquisa qualitativa em estudos organizacionais. São Paulo: Saraiva, cap. 8, p. 241-266, 2007.

BARNEY, J. B. Firm resources and sustained competitive advantage. Journal of Management, v. 17, n. 1, p. 99-120, Mar. 1991.

http://dx.doi.org/10.1177/014920639101700108

BARNEY, J. B. Purchasing, supply chain management and sustained competitive advantage: the relevance of resource-based theory. Journal of Supply Chain Management, v. 48, n. 2, p. 3-6, 2012.http://dx.doi.org/10.1111/j.1745493X.2012.03265.X

BARNEY, J. B; HANSEN, M. H. Trustworthiness as a source of competitive advantage. Strategic Management Journal, v. 15, p. 175-190, 1994.

http://dx.doi.org/10.1002/smi.4250150912

BARNEY, J. B.; HESTERLY, W. S. Administração estratégica e vantagem competitiva. São Paulo: Pearson Prentice Hall, 2007.

BRITO, R. P.; BERARDL, P. C. Vantagem competitiva na gestão sustentável da cadeia de suprimentos: um metaestudo. Revista de Administração de Empresas, v. 50, n. 2, p. 155-169, 2010. http://dx.doi.org/10.1590/S0034-75902010000200003 
BURGESS, K.; SINGH, P. J.; KOROGLU, R. Supply chain management: a structured literature review and implications for future research. International Journal of Operations and Production Management, v. 26, n. 7, p. 703-729, 2006. http://dx.doi.org/10.1108/01443570610672202

CHEN, I. J.; PAULRAJ, A. Towards a theory of supply chain management: the constructs and measurements. Journal of Operations Management, v. 22, p. 119150, 2004. http://dx.doi.org/10.1016/j.jom.2003.12.007

CHEN, Y.; LIN, M. J.; CHANG, C. The positive effects of relationship learning and absorptive capacity on innovation performance and competitive advantage in industrial markets. Industrial Marketing Management, v. 38, p. 152-158, 2009. http://dx.doi.org/10.1016/i.indmarman.2008.12.003

CHOPRA, S.; MEINDL, P. Gerenciamento da cadeia de suprimento: estratégia, planejamento e operação. São Paulo: Prentice Hall, 2004.

COUSINS, P. D.; LAWSON, B.; SQUIRE, B. Supply chain management: theory and practice - the emergence of an academic discipline? International Journal of Operations and Production Management, v. 26, n. 7, p. 697-702, 2006. http://dx.doi.org/10.1108/01443570610672194

DINIZ, C. C.; BASQUES, M. F. D. A industrialização nordestina recente e suas perspectivas. Fortaleza: Banco do Nordeste do Brasil, 2004.

DUSCHEK, S. Inter-firm resources and sustained competitive advantage.

Management Revue, v. 15, n. 1, p. 53-73, 2004.

DYER, J. H.; CHO, D. S.; CHU, W. Strategic supplier segmentation: the next "best practice" in supply chain management. California Management Review, v. 40, n. 2, p. 57-77, Winter 1998. http://dx.doi.org/10.2307/41165933

DYER, J. H.; SINGH, H. The relational view: cooperative strategy and sources of interorganizational competitive advantage. Academy of Management Review, v. 23, n. 4, p. 660-679, 1998. http://dx.doi.org/10.2307/259056

GODOI, C. K.; BALSINI, C. P. V. A pesquisa qualitativa nos estudos organizacionais brasileiros: uma análise bibliométrica. In: SILVA, A. B. da; GODOI, C. K.;

BANDEIRA-DE-MELLO, R. Pesquisa qualitativa em estudos organizacionais: paradigmas, estratégias e métodos. São Paulo: Saraiva, cap. 3, p. 89-112, 2007.

GODOY, A. S. Estudo de caso qualitativo. In: SILVA, A. B. da; GODOI, C. K.; BANDEIRA-DE-MELLO, R. Pesquisa qualitativa em estudos organizacionais: paradigmas, estratégias e métodos. São Paulo: Saraiva, cap. 4, p. 115-146, 2007.

GOLD, S.; SEURING, S.; BESKE, P. Sustainable supply chain management and inter-organizational resources: a literature review. Corporate Social Responsibility and Environmental Management, v. 17, p. 230-245, 2010. 
GRANT, R. M. The resource-based theory of competitive advantage: implications for strategy formulation. California Management Review, v. 33, n. 3, p. 114-135, Spring 1991. http://dx.doi.org/10.2307/41166664

HUNT, S. D.; DAVIS, D. F. Grounding supply chain management in resourceadvantage theory. Journal of Supply Chain Management, v. 44, n. 1, p. 10-21, 2008. http://dx.doi.org/10.1111/j.1745-493X.2008.00042.x

JOHNSTON, D.A; McCUTCHEON, D. M.; STUART, F. I.; KERWOOD, H. Effects of supplier trust on performance of cooperative supplier relationships. Journal of Operations Management, v. 22, p. 23-38, 2004. http://dx.doi.org/10.1016/j.jom.2003.12.001

LADO, A. A.; PAULRAJ, A.; CHEN, I. J. Customer focus, supply-chain relational capabilities and performance: evidence from US manufacturing industries. The International Journal of Logistics Management, v. 22, n. 2, p. 202-221, 2011. http://dx.doi.org/10.1108/09574091111156550

LAMBERT, D. M. The eight essential supply chain management processes. Supply Chain Management Review, v. 8, n. 6, p. 18-26, 2004.

http://dx.doi.org/10.1108/09574099810805807

LAMBERT, D. M.; COOPER, M. C.; PAGH, J. Supply chain management: implementation issues and research opportunities. The International Journal of Logistics Management, v. 9, n. 2, p. 1-19, 1998.

LAYDER, D. Sociological practice: linking theory and social research. London: Sage Publications, 1998.

MINISTÉRIO DO TRABALHO E EMPREGO - MTE. Relação Anual de Informações Econômicas e Sociais 2010. Disponível em www.mte.gov.br Acesso em 11/03/2012.

OLIVER, C. The institutional embeddedness of economic activity. Advances in Strategic Management, v. 13, p. 163-186, 1996.

PENG, M. W. Estratégia Global. São Paulo: Thompson Learning, 2008.

PETERAF, M. A. The cornestones of competitive advantage: a resource-based view. Strategic Management Journal, v. 14, n. 3, p. 179-191, 1993. http://dx.doi.org/10.1002/smi.4250140303

STRAUSS, A.; CORBIN, J. Pesquisa qualitativa: técnicas e procedimentos para o desenvolvimento de teoria fundamentada. 2. ed. Porto Alegre: Artmed, 2008.

VASCONCELOS, F. C.; CYRINO, A. B. Vantagem competitiva: os modelos teóricos atuais e a convergência entre estratégia e teoria organizacional. Revista de

Administração de Empresas, v. 40, n. 4, p. 20-37, Out./Dez. 2000. 
VIANA, F. L. E. Gestão da Cadeia de Suprimento e Vantagem Competitiva: uma análise em setores industriais a partir da visão relacional. 2010. 440 f. Tese (Doutorado Administração) - Programa de Pós-Graduação em Administração, UFRN, Natal.

WIELAND, A.; WALLENBURG, C. M. The influence of relational competencies on supply chain resilience: a relational view. International Journal of Physical Distribution \& Logistics Management, v. 43, n. 4, p. 300-320, 2012.

WILLIAMSON, O. E. Las instituciones económicas del capitalismo. México: Fondo de Cultura Económica, 1989.

WILLIAMSON, O. E. Comparative economic organization: the analysis of discrete structural alternatives. Administrative science quarterly, v. 36, n. 2, p. 269-296, 1991. http://dx.doi.org/10.2307/2393356

WILLIAMSON, O. E. The economics of governance. The American Economic Review, v. 25, n. 2, p. 1-18. 2005.

YIN, R. K. Estudo de caso: planejamento e métodos. 3. ed. Porto Alegre: Bookman, 2005.

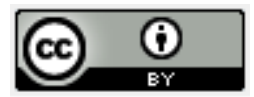

